\title{
Evaluation of analgesics use in orthopedic department at tertiary care hospital in Bareilly, Uttar Pradesh, India
}

\author{
Pooja Agrawal ${ }^{1}$, Vijender Kumar Agrawal $^{2} *$
}

\begin{abstract}
${ }^{1}$ Department of Pharmacology, Government Medical College Haldwani, Uttarakhand, India ${ }^{2}$ Department of Community Medicine, Rajshree Medical Research Institute, Bareilly, Uttar Pradesh, India
\end{abstract}

Received: 30 August 2016

Revised: 31 August 2016

Accepted: 28 September 2016

\section{*Correspondence to:}

Dr. Vijender Kumar Agrawal, Email: vijenderagrawal@ yahoo.co.in

Copyright: () the author(s), publisher and licensee Medip Academy. This is an openaccess article distributed under the terms of the Creative Commons Attribution NonCommercial License, which permits unrestricted noncommercial use, distribution, and reproduction in any medium, provided the original work is properly cited.

\begin{abstract}
Background: Analgesics including nonsteroidal anti-inflammatory drugs (NSAIDs) are commonly prescribed group of drugs in clinical practice for the management of pain and inflammation. This study was carried out to evaluate the prescribing pattern of analgesics in orthopedic in-patient department of tertiary care teaching hospital at Bareilly (Uttar Pradesh).

Methods: This hospital based cross-sectional study was carried out for 3 months from March to May 2015. Collected data included age, sex, diagnosis and line of management during the study. The generic name and the average cost of treatment per patient were evaluated using Indian Drug Review, 2014. The prescribed drugs were assessed with respective National Model List of Essential Medicines (NLEM), 2011 and the rationality of prescriptions was determined using the World Health Organization indicators of drug utilization. The patients' details were recorded in a data collection form and results were analysed by descriptive statistics.
\end{abstract}

Results: Out of 400 patients, 246 were male and 154 were female. The average number of analgesic per prescription was 1.48 . In this study, $52.5 \%$ of patients had received single analgesic. Diclofenac was the most commonly prescribed analgesic (45.39\%). During hospitalization, majority of the patients have received parenteral preparation. Gastro protective agents and antimicrobials were frequently prescribed along with analgesics. Out of 584 analgesics prescribed, $356(60.96 \%)$ were from the NLEM, India. Furthermore, 276 $(47.26 \%)$ analgesics were prescribed by generic name. The average cost of treatment per patient was 2050.70 INR. Utilization of analgesic in terms of defined daily dose/100 bed-days was 102.06 .

Conclusions: The percentages of analgesics prescribing from NLEM and the use of analgesic by generic name were found satisfactory.

Keywords: Analgesics, Orthopedics, Prescription pattern

\section{INTRODUCTION}

Pain is an unpleasant sensory and emotional experience associated with actual or potential tissue damage. ${ }^{1}$ Analgesics including nonsteroidal anti-inflammatory drugs (NSAIDs) are commonly prescribed group of drugs in clinical practice for the management of pain and inflammation., ${ }^{2,3}$ NSAIDs are also most widely prescribed class of medications worldwide and commonly used over the counter. ${ }^{4}$ These drugs have a wide range of adverse effects. Gastrointestinal toxicity is a major clinical limitation. 5,6

Therefore, periodic evaluation of drug utilization patterns needs to be done to enable suitable modifications in the prescription of drugs to increase the therapeutic benefit and decrease the adverse effects. Prescribing pattern studies are conducted to monitor, evaluate and if necessary, suggest modifications in the prescribing behavior of medical practitioners to make medical care rational and cost effective. ${ }^{7}$ Rational use of medicines (RUM) is an issue that has global importance, as it aims at evaluating the accessibility, availability, and correct prescribing of the drugs. ${ }^{8}$

In developing countries like India, where the financial resources are scarce and affordability of the patients is less, implementation of RUM becomes more important and therefore, the assessment of drug utilization is vital for clinical, economic, and educational purposes. ${ }^{9}$ 
Drug utilization research studies conducted in the inpatient settings are effective tools that help in evaluating drug prescribing trends, efficiency, and cost-effectiveness of hospital formularies. ${ }^{10}$ Defined daily dose (DDD) is an important tool to compare the drug utilization among different clinical setups within a country and between different countries. DDD/100 bed-days provide a rough estimate of drug consumption in hospital inpatients and it is a fixed unit of measurement independent of formulation and price. ${ }^{11,12}$ Therefore, this study was conducted to observe and analyse the prescribing pattern of analgesics at orthopedic in-patient department of tertiary care hospital of Bareilly (UP).

\section{METHODS}

This hospital based cross-sectional study was carried out from March 2015 to May, 2015 at orthopedic in-patient department of a tertiary care teaching hospital, Bareilly (UP). The Institutional Ethical Committee permission was taken to conduct this study.

\section{Inclusion criteria}

Patients who received analgesics in orthopedics ward during study period irrespective of age, sex, diagnosis, and treatment.

\section{Exclusion criteria}

Prescriptions of patients attending orthopedic OPD and those who were admitted in other in-patient department. The patients who were absconded or discharged against medical advice were excluded from the study.

\section{Collection of data}

A total 400 patients were enrolled during the study. Demographic data comprised age, sex, and address was collected from bed-head ticket information file. The clinical data included diagnosis, name of analgesics, route of administration, duration of treatment with analgesics, any adverse event with analgesics (if any), coprescribed drugs, and duration of hospital stay were recorded. These data were documented in a predesigned case record form. Analgesics prescribed by Physicians of orthopedic department of this hospital were considered in this study. The generic names of the drugs were obtained from the Indian Drug Review, 2014. ${ }^{13}$ The study was also assessed to check whether the drugs prescribed were enlisted under NLEM, India 2011 or not. The cost of drugs per patient was calculated as per hospital formulary and Indian Drug Review, 2014. The cost of laboratory investigations and ward charges were not included. Drug utilization pattern was measured in DDD/100 bed-days.

DDD/100 bed-days were calculated using the following equation. $^{11}$ $\frac{\text { Total dose in } \mathrm{mg} \text { during study period } \times 100}{D D D \text { of drug } \times \text { Study duration }}$
$\times$ bed strength $\times$ average bed occpancy rate

During the time of discharge, analgesic prescriptions pattern, and other relevant data were collected again.

\section{Statistical analysis}

Descriptive statistics were used to analyse the results. Percentage and averages of the variable were also calculated to compare the data with other findings.

\section{RESULTS}

Table 1: Distribution of patients according to sex, cause of admission and number of analgesic use.

\begin{tabular}{|lc|}
\hline Variable & \multicolumn{1}{|c|}{$\begin{array}{l}\text { Number of patients (\%) } \\
\mathbf{n}=400\end{array}$} \\
\hline Gender & $246(61.5)$ \\
\hline Male & $144(38.5)$ \\
\hline Female & $288(72)$ \\
\hline Indication of hospital admission \\
\hline $\begin{array}{l}\text { Fracture } \\
\text { (Self-fall fractures ) }\end{array}$ \\
\hline Road traffic accident & $84(21)$ \\
\hline Infective arthritis & $16(4)$ \\
\hline Congenital condition & $12(3)$ \\
\hline Number of analgesics provided \\
\hline One & $222(55.5)$ \\
\hline Two & $174(43.5)$ \\
\hline Three or more & $4(1)$ \\
\hline
\end{tabular}

Table 2: Distribution of patients according to indicators assessed.

\begin{tabular}{|ll|}
\hline Variable & Number /\% \\
\hline $\begin{array}{l}\text { Average number of analgesic per } \\
\text { prescription }\end{array}$ & 1.48 \\
\hline $\begin{array}{l}\text { Average number of drugs per } \\
\text { prescription }\end{array}$ & 4.78 \\
\hline $\begin{array}{l}\text { Percentages of patients on analgesics } \\
\text { from National Model list of Essential } \\
\text { Medicine }\end{array}$ & 60.96 \\
\hline $\begin{array}{l}\text { Percentage of analgesics prescribed by } \\
\text { generic name }\end{array}$ & 47.26 \\
\hline $\begin{array}{l}\text { Utilization of analgesics in term of } \\
\text { DDD/100-bed days }\end{array}$ & 102.06 \\
\hline $\begin{array}{l}\text { Average cost of treatment per patient in } \\
\text { Indian Rupees }\end{array}$ & 2050.70 \\
\hline Most common route of administration & Parenteral \\
\hline
\end{tabular}

Distribution of Patients according to sex, cause of admission and number of analgesic use has been given in Table 1. Out of 400 patients, 246 and 154 were male and female, respectively. Totally 584 analgesics were 
prescribed to the patients. The average number of analgesic per prescription was 1.48 . The median age of the patient was 30.5 year. A maximum number of analgesic prescriptions were found in the age group of 21-30 years. Self-fall fractures (72\%) were the most common condition followed by road traffic accident (21\%), infective arthritis (4\%), and congenital condition (3\%). Distribution of Patients according to indicators assessed has been given in Table 2. As per the World Health Organization (WHO) drug use indicators, out of total analgesics prescribed, $356(60.96 \%)$ were from the NLEM, India 2011 and 276 (47.26\%) analgesics were prescribed by generic name. The average number of drugs per prescription was 4.78. As per the core indicators of drug utilization, in this study $222(55.50 \%)$ of patients have received single analgesic; however, 174 $(43.5 \%)$ numbers of patients have received two analgesics at a time. More than three analgesics were prescribed in $4(1 \%)$ patients (Table 1). The median duration of analgesic therapy was 4 days and $40 \%$ of analgesic was given for 3-5 days of duration for the treatment. The median duration of hospital stay was 6days. Maximum analgesics $(55.82 \%)$ were given by parenteral route. The average cost of treatment per patient was 2050.70 Indian rupees (Table 2).

In this study, out of 584 most of the analgesics were peripherally acting analgesics (NSAIDS) 314 (53.77\%), combination analgesics (nonopioid and NSAIDS) were 264 (45.20\%), and centrally acting synthetic opioid analgesic i.e., tramadol $6(1.03 \%)$. Diclofenac was the most commonly prescribed analgesic 265 (45.39\%) followed by aceclofenac and paracetamol 246 (42.12\%), ibuprofen $48(8.22 \%)$, ibuprofen and paracetamol 18 $(3.08 \%)$, tramadol $9(1.03 \%)$. We have observed 446 $(22.36 \%)$ number of analgesics being coprescribed with gastroprotectives mainly PPIs (proton pump inhibitors) $328(73.54 \%)$ and H2 blockers 118 (26.46\%). Adverse drug reactions were not found during the study. Total utilization of analgesic during the study in terms of DDD/100 bed-days was 102.06.

\section{DISCUSSION}

Fractures are among the most common orthopedic problems, and about 6.8 million people seek medical care attention for fracture in India and most common indication for prescribing diclofenac was fractures. ${ }^{14,15}$ This study reveals that most common indication for hospitalization was fracture and diclofenac was the most commonly prescribed drug. Prescribing drugs by generic name, promote the rational use of drugs with regard to safety, efficacy, and cost by permitting the identification of the products by its scientific names. Increasing generic prescribing would rationalize the use and reduce the cost of drugs. ${ }^{16-18}$ In this study, $276(47.26 \%)$ analgesics were prescribed with generic name. Globally, NSAIDs are most commonly prescribed drugs for the management of pain and inflammation and the same has been reflected in this study. Despite the wide clinical use of NSAIDs, their gastrointestinal toxicity is the major limitation in clinical use. Hence, they are coprescribed with gastroprotectives agents. ${ }^{19}$ We found $22.36 \%$ of analgesics being coprescribed with gastroprotectives agents.

Essential medicines list has been shown to improve the quality and cost-effectiveness of health-care delivery when combined with proper procurement policies and good prescribing practices. Essential drugs list or formulary issued to measure the degree to which practices conform to a national drug policy, as indicated by prescribing from the national essential drugs list or formulary for the type of facility surveyed. In this study, $60.96 \%$ analgesics were prescribed from the NLEM, India 2011. ${ }^{20}$ The findings from Sen and Bathini prescribed analgesics from the NLEM were $81.94 \%$, Salman et al. were $62.20 \%$ from NLEM, India 2003 and out of the 37 study reports, in 8 studies, $60 \%$ of the drugs were prescribed from an essential medicines list. ${ }^{18,21,22}$

The average number of drugs per prescription is an important parameter while doing a prescription audit. Multiple drug prescribing results polypharmacy, this may cause to irrational prescribing and induce adverse effect. In this study, the average number of drug per prescription was 4.78. The similar findings were reported in several countries (Indonesia, Niger, Nigeria, India, Ghana, and Pakistan) in which three or more drug were prescribed per prescription. ${ }^{18}$

This study reveals that the average cost of treatment per patient was Rs. 2050.70 INR. These differences in mean cost of total drugs in this study in comparison with other studies may be due to variation in type and severity of the admitted patient, indications for the admission, different prescribing pattern, or inflation in the price of medications. $^{23,24}$

This study revealed that most of the analgesics were prescribed for appropriate indication. The duration of prescribing of analgesics is found to be satisfactory in this study. Although the average cost of treatment per patient was high. Coprescribed drugs, i.e. proton pump inhibitors were commonly used for maximum. Analyzing the results of these indicators information is obtained about the "quality of prescribing the drug" to quantity in different circumstances of use (time, duration, age of the patient, route of administration, etc.). The calculation of DDD/100 bed-days for drug utilization is used as a tool to measurement the pattern of consumption of analgesics. In this study, the total drug utilization of analgesics at inpatients department during the study in terms of DDD/100 bed-days was 102.06.

\section{CONCLUSION}

The percentage of analgesics prescribed from essential medicines list and the use of the generic name were found to be satisfactory, but the average number of drug per prescription was high. 
Funding: No funding sources

Conflict of interest: None declared

Ethical approval: Not required

\section{REFERENCES}

1. Tabish A, Jha RK, Rathod AM, Rathod RM, Gupta KK. Prescribing trend of analgesics in a tertiary health care setup of rural Vidarbha. Res J Pharm Biol Chem Sci. 2012;3:566-71.

2. Ravi Shankar P, Partha P, Nagesh S. Prescribing patterns in medical outpatients. Int J Clin Pract. 2002;56:549-51.

3. Sharma T, Dutta S, Dhasmana DC. Prescribing pattern of NSAIDs in orthopaedic OPD of a tertiary care teaching hospital in Uttaranchal. JK Sci 2006;8:160-2.

4. Kumar A, Dalai CK, Ghosh AK, Ray M. Drug utilization study of co-administration of nonsteroidal anti-inflammatory drugs and gastroprotective agents in an orthopaedics outpatients department of a tertiary care hospital in West Bengal. Int J Basic Clin Pharmacol. 2013;2:199-202.

5. Graumlich JF. Preventing gastrointestinal complications of NSAIDs. Risk factors, recent advances, and latest strategies. Postgrad Med. 2001;109:117-20, 123-8.

6. Manohar VS, Vinay M, Jayasree T, Kishan PV, Ubedulla S, Dixit R. Prescribing pattern of gastroprotective agents with non-steroidal antiinflammatory drugs. J Pharmacol Pharmacother. 2013;4:59-60.

7. Shankar PR, Pai R, Dubey AK, Upadhyay DK. Prescribing patterns in the orthopaedics outpatient department in a teaching hospital in Pokhara, Western Nepal. Kathmandu Univ Med J. 2007;5:1621.

8. Thawani V. Rational use of medicines: Achievements and challenges. Indian J Pharmacol. 2010;42:63-4.

9. Uppal R, Nayak P, Sharma PL. Prescribing trends in internal medicine. Int J Clin Pharmacol Ther Toxicol. 1984;22:375-6.

10. Kaur S, Rajagopalan S, Kaur N, Shafiq N, Bhalla A, Pandhi $P$, et al. Drug utilization study in medical emergency unit of a tertiary care hospital in North India. Emerg Med Int. 2014:973578.

11. WHO Collaborating Centre for Drug Statistics Methodology (Norway). Guidelines for ATC Classification and DDD Assignment. Oslo: WHO Collaborating Centre for Drug Statistics Methodology; 2002a.
12. WHO Collaborating Centre for Drug Statistics Methodology (Norway). ATC Index with DDDs. Oslo: WHO Collaborating Centre for Drug Statistics Methodology; 2002b.

13. Desai S. Indian Drug Review, Drug triple i compendium, UBM Medica India Pvt Ltd. 2014:21(4).

14. Mathew G, Sancheti P, Jain A, Bhandari M. Multicenter collaborative for orthopaedic research in India: An opportunity for global leadership. Indian $\mathbf{J}$ Orthop. 2008;42:165-8.

15. Raut A, Reddy G, Patil S, David N. Comparative efficacy of combined use of diclofenac with thiocolchicoside and diclofenac alone in patients. Int Res J Pharm. 2013;4:164-6.

16. Bhansali NB, Gosai TR, Dholaria NK, Suthar SD, Chacko J, Chavda DA, et al. Drug utilization study in post-operative patients in surgical ward of a tertiary hospital attached with medical college. Pharm Lett. 2013;5:251-7.

17. Maheshwari N, Wagh RJ, Chincholkar AS, Gupta M. Prescription pattern monitoring of nonsteroidal antiinflammatory drugs (NSAIDs) in urban health centre in Talegaon. Int J Pharma Bio Sci. 2015;6:596-602.

18. WHO Medicines Situation. Available from: http://apps.who.int/medicinedocs/documents/s20054e n/s20054en.pdf. Last accessed on 2014 Mar 25.

19. Muraraiah S, Rajarathna K, Vishwanath $\mathrm{M}$, Ramaswamy A, Kamath SD, Seshu S, et al. Evaluation of WHO prescribing indicators among orthopaedic in-patients at a tertiary care hospital. J Chem Pharm Res. 2014;6:278-80.

20. National List of Essential Medicines of India. 2011. pp. 1-123. Available from: http://apps. who.int/medicinedocs/documents/s18693e n/s18693en.pdf. Last accessed on 2014 Mar 25.

21. Sen S, Bathini P. Auditing analgesic use in postoperative setting in a teaching hospital. J Clin Diagn Res. 2015;9:FC01-4.

22. Salman MT, Akram MF, Rahman S, Khan FA, Haseen MA, Khan SW. Drug prescribing pattern in surgical wards of a teaching hospital in North India. Indian J Pract Doctor 2008;5:5-6.

23. Jhaveri BN, Patel TK, Barvaliya MJ, Tripathi CB. Drug utilization pattern and pharmacoeconomic analysis in geriatric medical in-patients of a tertiary care hospital of India. J Pharmacol Pharmacother. 2014;5:15-20.

24. Shankar PR, Upadhyay DK, Subish P, Bhandari RB, Das B. Drug utilisation among older inpatients in a teaching hospital in Western Nepal. Singapore Med J. 2010;51:28-34.

Cite this article as: Agrawal P, Agrawal VK.

Evaluation of analgesics use in orthopedic

department at tertiary care hospital in Bareilly, Uttar

Pradesh, India. Int J Basic Clin Pharmacol

2016;5:2538-41. 